\title{
Kajian Pemanfataan Padang Lamun Sebagai Lahan Budidaya Ikan Baronang di Pulau Sembilan Kabupaten Sinjai
}

Assessment of Land Utilization Seagrass As Aquaculture Baronang In Pulau Sembilan, Sinjai

\author{
Firdaut Ismail ${ }^{1}$ Nebuchadnezzar Akbar ${ }^{2}$, Rustam E. Pembonan ${ }^{3}$ dan Irmalita Tahir ${ }^{4}$ \\ ${ }^{12}$ Program Studi Ilmu Kelautan, FPIK. Universitas Khairun, Ternate \\ ${ }^{34}$ Program Studi Ilmu Kelautan, FPIK. Universitas Khairun, Ternate
}

\section{E-mail:Moldykelautan@gmail.com}

\begin{abstract}
ABSTRAK
Komunitas lamun berada di antara batas terendah daerah pasang surut sampai kedalaman tertentu di mana cahaya matahari masih dapat mencapai dasar laut. Padang lamun merupakan suatu komunitas dengan produktivitas primer dan sekunder yang sangat tinggi, detritus yang dihasilkan sangat banyak, dan mampu mendukung berbagai macam komunitas hewan. Salah satu penyebabnya adalah pemanfaatan daerah pantai yang dapat memberikan pengaruh terhadap keberadaan padang lamun. Ancaman terhadap eksistensi padang lamun ini diduga menyebabkan ikan baronang menurunnya nilai produksi hal ini akan memberikan pengaruh terhadap kondisi stok ikan baronang. Penelitian ini bertujuan untuk (1) Mengidentifikasikan kondisi ekosistem lamun di perairan di Pulau Sembilan, (2) Menganalisis hubungan kondisi ekologis padang lamun terhadap pertumbuhan ikan baronang di Pulau Sembilan.

Pengumpulan data dilakukan sejak bulan Agustus hingga September 2015 di padang lamun perairan Pulau Liang-liang, Kabupaten Sinjai. Pengumpulan data yang diperoleh secara langsung dilapangan dengan melakukan pengukuran kualitas air, kerapatan arus, kerapatan, penutupan lamun dan pertumbuhan ikan baronang.

Pengamatan terhadap padang lamun di perairan Pulau Liang-liang merupakan vegetisi campuran (heterospesifik) yang didominasi oleh Cymodocea serrulata di stasiun I, II dan III serta didominasi oleh Syringodium isoetifolium dan Halodule Uninervis, dengan total kerapatan 214 ( teg/m2), penutupan 20.15 ( $\%$ ) pada stasiun I, Stasiun II dengan total kerapatan 129 ( teg/m2), penutupan 9.66 ( \% ) sedangkan pada stasiun III dengan total kerapatan 188 ( teg/m2), penutupan 10.84 ( $\%$ ). Pengamatan terhadap pertumbuhan ikan baronang S.canaliculatus dibedakan atas stasiun I mencapai kisaran $10 \mathrm{~g}$, sedangkan pengamatan pada Stasiun II dengan pertambahan bobot berat selama penelitian adalah $5 \mathrm{~g}$ dan pengamatan pada Stasiun III (Pasir berlempung) pertumbuhan berat $8 \mathrm{~g}$.
\end{abstract}

Kata kunci : kajian, padang lamun, ikan baronang, pulau sembilan 


\section{ABSTRACT}

Seagrass communities are among the lowest limit tidal areas up to a certain depth where sunlight can still reach the seabed. Seagrass is a community with primary and secondary productivity is very high, the resulting detritus very much, and capable of supporting a wide range of animal communities. One possible cause is the use of coastal areas that could impact the presence of seagrass. The threat to the existence of seagrass is thought to cause baronang declining fish production values it will give effect to the condition of fish stocks baronang. This study aims to (1) Identify the condition of seagrass in the waters in Pulau Sembilan, (2) analyze the relationship between ecological conditions on the growth of seagrass baronang fish in Pulau Sembilan.

Data collection was conducted from August to September 2015 in Island waters seagrass Liang-liang, Sinjai. The collection of data obtained directly in the field by measuring water quality, current density, density, closing baronang seagrass and fish growth. Observation of seagrass in Island waters Liang-liang is vegetisi mixture (heterospesifik) dominated by Cymodocea serrulata at the station I, II and III as well as dominated by Syringodium isoetifolium and Halodule uninervis, with a total density of 214 (TEG / m2), closing 20:15 (\%) at the first station, Station II with a total density of 129 (TEG / m2), closing 9.66 (\%) whereas the third station with a total density of 188 (TEG / m2), closing 10.84 $(\%)$. Observations on the growth of fish baronang S.canaliculatus distinguished station I reached the range of $10 \mathrm{~g}$, whereas observations on Station II with weight gain weight during the study was $5 \mathrm{~g}$ and observations at Station III (Sand argillaceous) heavy growth of $8 \mathrm{~g}$.

Keywords : study, seagrass, fish baronang, nine islands

\section{Pendahuluan}

Kawasan pesisir pantai beserta keragaman vegetasinya terutama ekosistem lamun (seagrass) memiliki beberapa fungsi ekologis sebagai daerah pemijahan (spawning ground), daerah asuhan (nursery ground) dan daerah perlindungan (sanctuary ground) bagi berbagai jenis ikan dan biota laut lainnya yang memiliki nilai ekonomis tinggi. Ekosistem lamun adalah ekosistem pesisir yang ditumbuhi oleh lamun sebagai vegetasi yang dominan. Lamun (seagrass) adalah kelompok tumbuhan berbiji tertutup (angiospermae) dan berkeping tunggal (monokotil) yang mampu hidup secara permanen di bawah permukaan air laut.

Peranan ekosistem lamun secara fisik di perairan laut dangkal adalah membantu mengurangi tenaga gelombang dan arus, menyaring sedimen yang terlarut dalam air dan menstabilkan dasar sedimen ( Zulkifly 2003). Peranannya di perairan laut dangkal adalah kemampuan berproduksi primer yang tinggi yang 
secara langsung berhubungan erat dengan tingkat kelimpahan produktivitas perikanannya. Kemampuan berproduksi primer yang tinggi dari ekosistem lamun, sangat dipengaruhi oleh kualitas perairan dimana ekosistem lamun hidup dan berkembang. Faktor kualitas air menjadi salah satu faktor penting karena lamun merupakan ekosistem yang secara permanen hidup di bawah permukaan air laut.

Pertumbuhan, morfologi, kelimpahan dan produksi primer lamun pada suatu perairan umumnya ditentukan oleh ketersediaan zat hara fosfat, nitrat dan amonium yang memainkan peranan penting dalam menentukan fungsi padang lamun. Kunci utama untuk mengetahui fungsi sistem lamun terletak pada pemahaman faktor-faktor yang mengatur produksi dan dekomposisi bahan organik. Namun demikian informasi mengenai lamun di Indonesia masih sangat kurang (Hutomo 1987).

\section{Metodologi Penelitian}

\subsection{Lokasi dan Waktu Penelitian}

Penelitian ini dilaksanakan pada bulan Agustus sampai dengan bulan September 2015, lokasi pengambilan sampel di perairan Pulau Sembilan. Analisis sampel dilakukan di Laboratorium Universitas Hasanuddin Makassar.

\subsection{Jenis dan Sumber Data}

Berdasarkan tujuan penelitian yang akan dicapai dan metode penelitian yang digunakan maka data yang dikumpulkan dalam penelitian ini terdiri dari dua jenis sumber data yakni :

a. Data Primer ; yaitu data yang diperoleh secara langsung dilapangan dengan melakukan pengukuran kualitas air, kerapatan arus, penutupan lamun dan pertumbuhan ikan baronang.

b. Data Sekunder ; yaitu data penunjang yang dikumpulkan dari instansi terkait yang berhubungan dengan materi penelitian maupun laporan tertulis yang dipandang relevan dengan penelitian.

\subsection{Metode Pengumpulan Data}

Teknik pengumpulan data dalam penelitian ini dilakukan dengan cara sebagai berikut :

a. Observasi. Teknik ini digunakan untuk mengakomodasi tujuan penelitian. 
b. Dokumentasi. Teknik ini digunakan untuk mengakomodasi latar belakang penelitian dan keadaan daerah penelitian yang diperoleh dengan cara mengumpulkan data-data yang berkaitan dengan penelitian baik dari instansi terkait maupun media cetak dan internet.

\subsection{Analisis Data}

Rumus yang digunakan dalam perhitungan kerapatan dan penutupan lamun adalah ;

1. Kerapatan Jenis Lamun yaitu jumlah individu lamun (tegakan) per satuan luas. Kerapatan jenis lamun dihitung dengan rumus berikut : (Brower et al 1990).

$$
\mathrm{Di}=\mathrm{Ni} / \mathrm{A}
$$

Keterangan ;

Di : Jumlah Individu (tegakan) ke-i per satuan luas

$\mathrm{Ni}$ : Jumlah individu (tegakan) ke-i dalam transek kuadrat

A : Luas transek kuadrat

2. Penutupan lamun merupakan luasan area yang ditutupi oleh lamun. Persen penutupan lamun dapat dihitung dengan menggunakan metode Saito dan Atobe sebagai berikut (English et al. 1994):

$$
\mathrm{C}=\frac{\Sigma(\text { mi.fi })}{\Sigma \mathrm{f}}
$$

3. Pertumbuhan Mutlak

Pertumbuhan mutlak adalah laju pertumbuhan total ikan. Rumus untuk mencari pertumbuhan mutlak adalah (Basyari et al, 1987).

$$
\mathrm{GR}=(\mathrm{Wt}-\mathrm{Wo})
$$

Keterangan :

GR : Growth Rate / pertumbuhan mutlak

Wt : bobot rata - rata akhir (gr/ekor)

$\mathrm{W}_{0}$ : bobot rata - rata awal (gr/ekor)

Analisis data yang digunakan untuk mengetahui faktor lingkungan, kerapatan lamun, penutupan lamun dan pertumbuhan ikan baronang antar stasiun dianalisis dengan dengan analisis sidik ragam (ANOVA) bila berbeda nyata pada taraf $5-10 \%(0,05<\mathrm{p}<0,10$ dilanjutkan dengan uji Duncan (Steel dan Torrie, 1989) dalam Munira (2010), dilanjutkan dengan uji Beda Nyata Terkecil BNT, pada taraf kepercayaan $95 \%$ dan $99 \%$. 
$\mathrm{BNTa}=\operatorname{ta}_{(\mathrm{v}) .} \mathrm{s}-\mathrm{d}$

Dimana ta

= Nilai baku t- student pada taraf uji a dan derajat bebas galat v.

\section{Hasil Dan Pembahasan}

\subsection{Keadaan Umum Wilayah Penelitian}

Kondisi Umum Pulau Liang -liang terletak di Kabupaten Sinjai, Provinsi Sulawesi Selatan. Pulau ini merupakan pulau yang berpenduduk. Pulau Liangliang masuk dalam Desa Pulau Harapan, Kecamatan Pulau Sembilan, Kab. Sinjai, Sulawesi Selatan. Ibu kota kecamatan Pulau Sembilan terdapat di P. Kambuno.

Berdasarkan posisi goegrafis, Pulau Liang-liang terletak pada posisi $5^{\circ} 8^{\prime}$ 19,000" LS dan 120²3' 50.000" BT (DKP Sinjai 2014). Batas wilayah Pulau Liang-liang berbatasan langsung dengan pulau disekitarnya, yaitu sebelah timur adalah Teluk Bone, sebelah utara adalah Pulau Burungloe, sebelah barat adalah daratan Pulau Sulawesi (tepatnya Kab. Sinjai) dan sebelah selatan adalah masih dalam kawasan Teluk Bone.

Sebagai gambaran umum bahwa Pulau Liang-liang adalah pulau berbukit dengan tingkat kemiringan sekitar $30^{\circ}$, tidak memiliki hamparan pantai, tetapi merupakan pantai curam berbatu. Di pulau ini tidak ditemukan vegetasi mangrove, hal ini disebabkan sebagian besar pantai curam berupa bebatuan yang kurang memungkinkan untuk tumbuh vegetasi mangrove. Di sepanjang tepi pulau sebagian besar merupakan bangunan pondasi rumah nelayan (DKP Sinjai 2014).

\subsubsection{Karakteristik Parameter Lingkungan}

Penentuan lokasi dilakukan berdasarkan pengamatan karakteristik perairan sebagai syarat tumbuh ikan baronang. Karakterisitik perairan yang diamati meliputi kondisi ekologis perairan yang terdiri dari parameter fisika, kimia dan biologi perairan.

Peranan kualitas perairan dalam kegiatan perikanan di suatu wilayah sangat penting untuk dijaga kestabilannya. Aktivitas pesisir dan Pulau-Pulau disekitarnya sangat mempengaruhi dampak dari kestabilan lingkungan perairan.Salah satu kegiatan perikanan yang sangat tergantung yakni kegiatan 
budidaya. Budidaya laut merupakan salah satu usaha perikanan dengan cara pengembangan sumberdayanya dalam area terbatas baik di alam terbuka maupun tertutup. Tempat untuk budidaya laut, demikian pula untuk air tawar, harus mempunyai fasilitas alami tertentu, terutama persediaan air yang sangat cukup, dengan suhu, salinitas dan kesuburan yang sesuai.

Tabel 4, Nilai parameter lingkungan selama penelitian pada setiap stasiun pengamatan.

\begin{tabular}{|c|c|c|c|c|c|c|}
\hline \multirow{2}{*}{$\begin{array}{l}\text { Parameter } \\
\text { lingkungan }\end{array}$} & \multicolumn{6}{|c|}{ Stasiun Pengamatan } \\
\hline & Stasiun I & Rata-rata & Stasiun II & Rata-rata & Stasiun III & $\begin{array}{l}\text { Rata- } \\
\text { rata }\end{array}$ \\
\hline Suhu $\left({ }^{\circ} \mathbf{C}\right)$ & $26,4-29,3^{0} \mathrm{C}$ & 27,86 & $26,2-28,4^{0} \mathrm{C}$ & 27,15 & $26,2-29,8^{0} \mathrm{C}$ & 27,16 \\
\hline pH & $7.50-8.00$ & 7.4 & 7-01.8.22 & 7.4 & 7.04-08.00 & 7.3 \\
\hline Salinitas $\%_{8 \circ}$ & $30.0-34.0$ & 31.98 & $30.5-33.0$ & 32.06 & $30.0-32.1$ & 32.9 \\
\hline Oksigen (mg/l) & $8.00-10.87$ & 9.92 & $7.03-9.36$ & 8.48 & $8.33-9.18$ & 8.86 \\
\hline Nitrat (mg/l) & $0.006-0.014$ & 0.009 & $0.007-0.013$ & 0.009 & $0.002-0.009$ & 0.006 \\
\hline Fosfat (mg/l) & $0.012-0.015$ & 0.013 & $0.011-0.015$ & 0.011 & $0.011-0.002$ & 0.009 \\
\hline Kedalaman (m) & $1.10-2.40$ & 2.30 & $1.35-1.50$ & 1.40 & $1.68-1.94$ & 1.85 \\
\hline $\begin{array}{l}\text { Kecepatan arus } \\
\quad(\mathbf{m} / \mathbf{d e t})\end{array}$ & $0.09-0.12$ & 0.10 & $0.09-0.13$ & 0.11 & $0.10-0.12$ & 0.038 \\
\hline
\end{tabular}

\subsubsection{Karakteristik Komunitas Lamun}

1. Kompisisi Jenis Lamun

Hasil pengukuran pada ketiga stasiun penelitian menunjukkan bahwa padang lamun, di Perairan Pulau Liang- liang merupakan vegetasi campuran (heterospesifik) dari tujuh jenis lamun (Gambar 6), yaitu Cymodocea serrulata tipe daun berbentuk daun normal, Halodule uninervis bertipe daun pita kecil dan Syringodium isoetifolium, dengan tipe daun berbentuk pita ukuran sedang (family Patomogetonaceae). Nienhuis et al, (1989). menyatakan bahwa campuran beberapa spesies lamun dalam suatu lokasi sering didapatkan di padang lamun indonesia. Pada beberapa tempat sering dijumpai adanya campuran lebih dari delapan spesies dalam suatu komunitas padang lamun 
yang saling berasosiasi seperti di perairan Laut, Flores, sedangkan di Teluk Kuta dari Teluk Gerupuk, Lombok Selatan dijumpai 11 spesies lamun yang saling berasosiasi (Kiswara 1989), Jenis-jenis lamun yang terdapat pada lokasi penelitian dan perbandingannya dengan perairan lainnya di Indonesia.

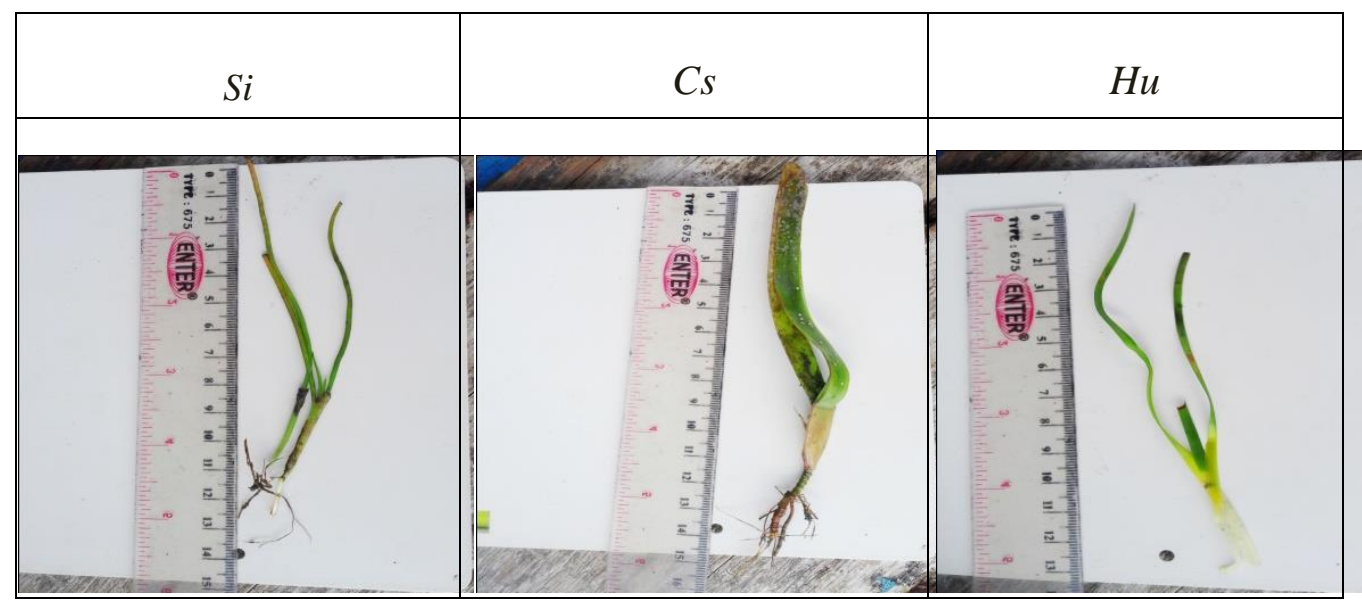

Ket : $\mathrm{Si}=$ Syringodium isoetifolium, $\mathrm{Cs}=$ Cymodocea serrulata, $\mathrm{Hu}=$ Halodule uninervis

2. Kerapatan Jenis Lamun

Hasil analisa kerapatan jenis lamun yang diperoleh selama penelitian seperti yang disajikan pada Gambar 7 memperlihatkan bahwa pada stasiun I ditemukan tiga Jenis Lamun tertinggi diwakili oleh Cymodocea serrulata $\left(92 \mathrm{teg} / \mathrm{m}^{2}\right)$ dan yang terendah Syringodium isoetifolium $\left(47 \mathrm{teg} / \mathrm{m}^{2}\right)$ dengan total kerapatan $\left(214 \mathrm{teg} / \mathrm{m}^{2}\right)$, pada stasiun II ditemukan jenis tertinggi diwakili oleh Cymodocea serrulata $\left(83 \mathrm{teg} / \mathrm{m}^{2}\right)$ dan yang terendah Halodule uninervis $\left(11 \mathrm{teg} / \mathrm{m}^{2}\right)$ dengan kerapatan $\left(129 \mathrm{teg} / \mathrm{m}^{2}\right)$, sedangkan pada stasiun III kerapatan jenis tertinggi adalah Cymodocea serrulata $\left(72 \mathrm{teg} / \mathrm{m}^{2}\right)$ dan yang terendah Syringodium isoetifolium $\left(51 \mathrm{teg} / \mathrm{m}^{2}\right)$ total kerapatan $\left(188 \mathrm{teg} / \mathrm{m}^{2}\right)$ dan kerapatan total lamun di stasiun 


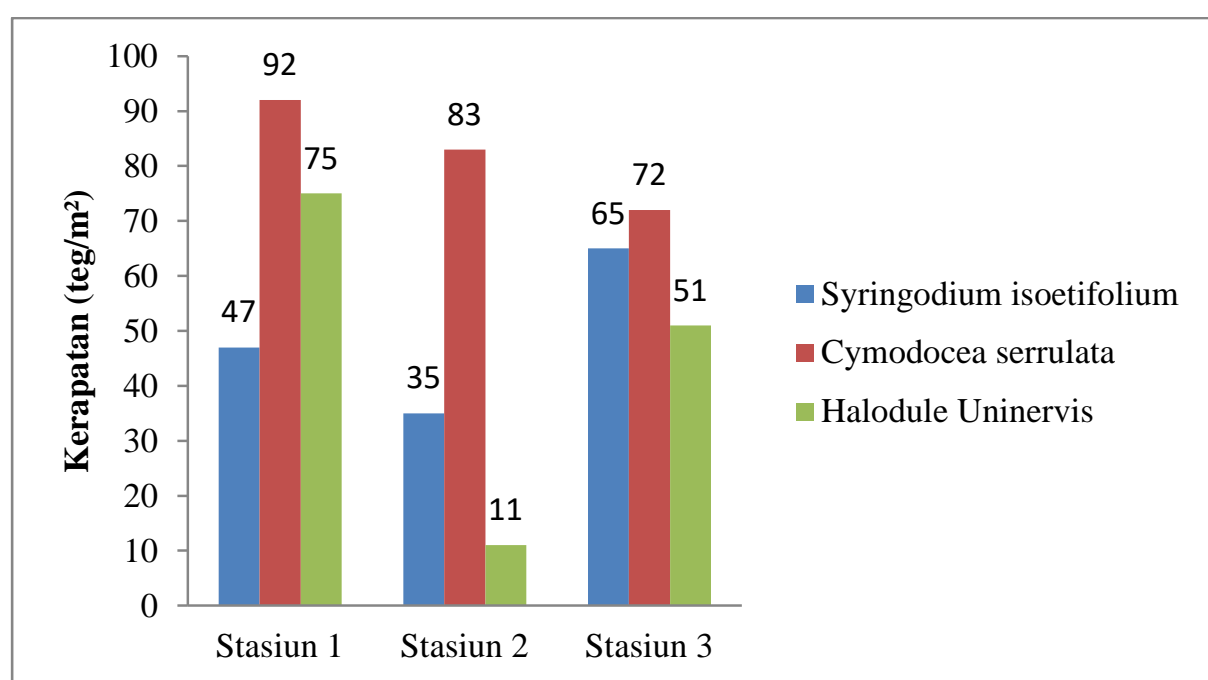

Gambar 7. Kerapatan jenis lamun diperairan Pulau Liang-Liang

Berdasarkan Gambar 7 dapat dilihat bahwa setiap jenis lamun memiliki kerapatan jenis yang berbeda-beda. Kerapatan jenis lamun per satuan luas sangat bervariasi tergantung kepada jenis lamun. Hal ini disebabkan oleh masing-masing spesies lamun memiliki tipe morfologi daun yang berbeda. Selain itu, disebabkan pula oleh tipe substrat yang berbeda. Tipe substrat berperan dalam mengelolah nutrien dan kestabilan lamun di perairan. Sebagaimana menurut Kiswara (1997) bahwa kerapatan lamun juga dipengaruhi oleh kedalaman, kecerahan, dan tipe substrat. Pengamatan padang lamun menggunakan metode visual, tidak hanya yang terdapat di transek saja yang diamati tetapi di sekitar lokasi penelitian. Pengidentifikasi padang dengan cara melihat foto-foto yang diambil pada saat pengamatan.

3. Penutupan Jenis Lamun

Persen penutupan menggambarkan tingkat penutupan/penaungan ruang oleh lamun. Informasi mengenai penutupan sangat penting untuk mengetahui kondisi ekosistem secara keseluruhan serta sejauh mana lamun mampu memanfaatkan luasan yang ada. Nilai kerapatan saja belum tentu dapat menggambarkan tingkat penutupan suatu spesies karena nilai penutupan selain dipengaruhi oleh kerapatan juga sangat erat kaitannya dengan tipe morfologi spesiesnya. Persentase penutupan lamun yang ditemukan di lokasi penelitian dapat dilihat pada Gambar 8. 


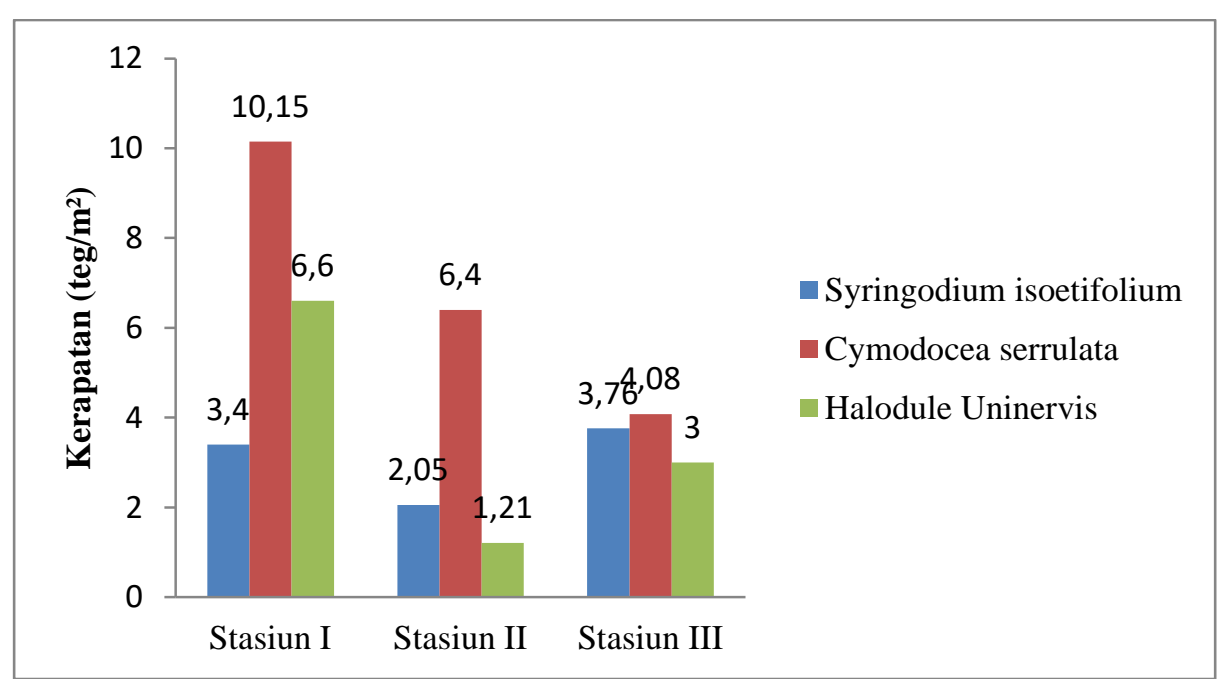

Gambar 8. Penutupan Lamun Di Perairan Pulau Liang-liang

Penutupan menggambarkan tingkat penutupan atau penaungan ruang oleh Komunitas lamun. Penutupan jenis lamun pada ketiga stasiun penelitian dapat dilihat pada tabel 5. Penutupan jenis lamun di stasiun I dan II didominasi oleh Cymdocea serrulata masing-masing sebesar $10.15 \%$ dan $6.40 \%$. Sedangkan di stasiun III Halodule uninervis merupakan jenis yang memiliki nilai penutupan relatif rendah yaitu $3.00 \%$. Secara keseluruhan, penutupan rata-rata jenis lamun di perairan pulau liangliang didominasi oleh Cymodocea serrulata (6,87 \%), kemudian Halodule uninervis (3,60 \%), dan terendah Syringodium isoetifolium (3,07\%). Hasil perhitungan penutupan total lamun di stasiun penelitian dapat dilihat pada Lampiran 5.

Keberadaan lamun pada kondisi habitat tersebut, tidak terlepas dari gangguan atau ancaman-ancaman terhadap kelansungan hidupnya baik berupa ancaman alami maupun ancaman dari aktivitas manusia.

\subsubsection{Pertumbuhan Ikan Baronang}

Pertumbuhan Berat ikan baronang dalam setiap stasiun pengamatan dan waktu pengamatan didapatkan hasil yang berbeda-beda ditampilkan pada Gambar 8. Pada Stasiun I Pertumbuhan berat pada pengamatan mencapai kisaran $10 \mathrm{~g}$, pertumbuhan yang paling baik ialah pada stasiun I dengan berat awal $20 \mathrm{~g}$ dan berat akhir $30 \mathrm{~g}$. Hal ini disebabkan bobot ikan baronang yang dengan terpenuhinya makanan dalam jumlah besar kemudian makanan yang tersedia adalah makanan alami yaitu padang lamun dari dalam karamba atau yang terbawa oleh arus ke dalam karamba dan tanpa diberi pakan. sedangkan pengamatan pada Stasiun II, penurunan angka pertumbuhan ini dikarenakan ikan kurang 
mendapatkan makanan dari karamba yang bukan lamun. Hal ini menjelaskan pula bahwa faktor tumbuh sangat bergantung pada makanan yang dimakan ikan baronang. Namun meskipun baronang tidak diberikan lamun, baronang masih dapat tumbuh dengan memanfaatkan makanan yang terbawa arus atau lumut yang menempel pada jaring karamba. Seperti yang dikemukakan oleh Basyari et al, (1987) bahwa ikan baronang yang tertangkap dan dibudidayakan di tambak maupun keramba jaringan apung mampu memakan makanan apa saja termasuk lumut yang menempel pada jaring, dengan pertumbuhan pada kisaran $5 \mathrm{~g}$ dengan berat awal $20 \mathrm{~g}$ dan berat akhir $25 \mathrm{~g}$. Sedangkan pengamatan pada Stasiun III (Pasir berlempung) pertumbuhan dengan kirasan $8 \mathrm{~g}$ dengan berat awal $20 \mathrm{~g}$ dan berat akhir $28 \mathrm{~g}$, selengakapnya dapat dilihat pada Lampiran 2.

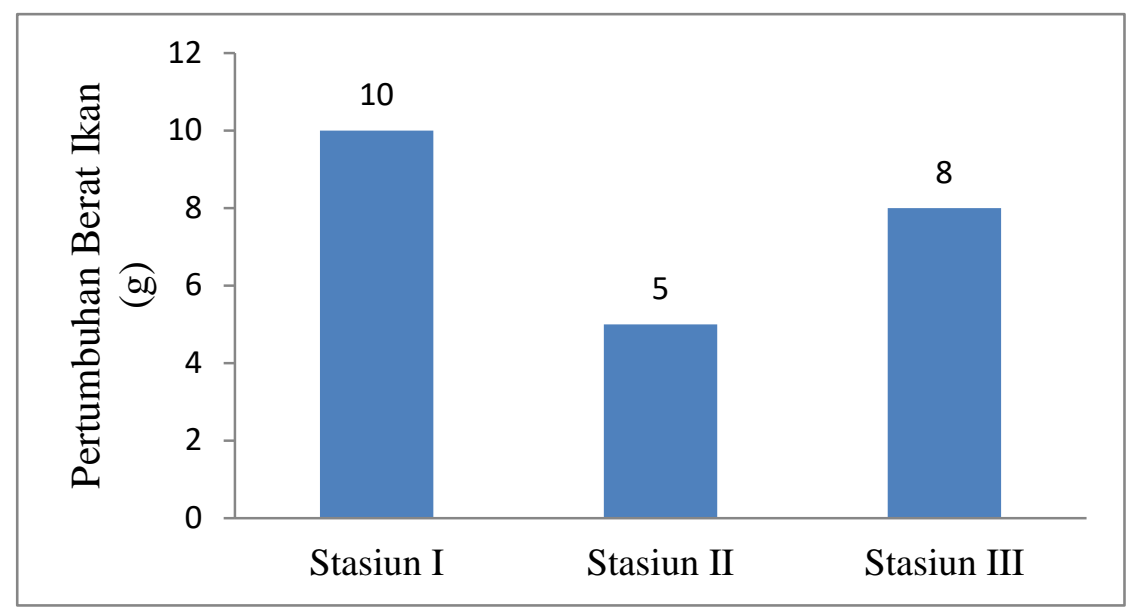

Gambar 9. Pertumbuhan Berat Ikan Baronang

Secara keseluruhan berdasarkan uraian di atas, dapat disimpulkan bahwa pertumbuhan panjang ikan dalam setiap stasiun dengan struktur kerapatan lamun yang berbeda mempunyai kecepatan pertumbuhan yang berbeda. terlihat bahwa secara umum jenis makanan yang ditemukan dalam lambung S.canaliculatus adalah potongan lamun dengan total komposisi diatas $90 \%$. Menurut Kordi (2009), ikan baronang tergolong herbivora dengan makanan utamanya berupa lamun, alga atau lumut, ikan pada tingkat larva memakan plankton dan menjadi herbivora saat mulai aktif mencari makan. Merta (1982) dalam Azkab (1987), di Teluk Banten, mendapatkan S.canaliculatus memakan jenis lamun Enhalus acoroids, Thalassia hemprichii, Halophila ovalis, Cymodocea serrulata, Halodule uninervis, dan Syringodium isoetifolium, organisme lain dalam isi lambungnya adalah alga, dan gastropoda. Jenis makanan 
yang lebih beragam diduga terkait dengan kerapatan vegetasi lamun yang tinggi sehingga mendukung keragaman sumber makanan dan kehadiran berbagai jenis ikan yang dapat membentuk rantai makanan lebih kompleks. Menurut Hemingga dan Duarte (2000), padang lamun dengan kerapatan tinggi meningkatkan luas permukaan bagi perlekatan hewan dan tumbuhan renik yang merupakan makanan ikan.

4. Pertumbuhan Panjang Ikan Baronang

Hasil penelitian pertumbuhan panjang ikan baronang mendapatkan ukuran S. canaliculatus dengan panjang pada stasiun penelitian dengan ukuran panjang awal $12 \mathrm{~cm}$ dan ukuran panjang akhir $13 \mathrm{~cm}$ di stasiun I dengan jarak pertumbuhan 1 cm, selengkapnya dapat dilihat pada lampiran 3. Pada stasiun II dan $13 \mathrm{~cm}$ untuk stasiun II, yang masuk ikan sedang. Menurut Allen (1999) S. canaliculatus mencapai ukuran dewasa adalah $20 \mathrm{~cm}$, sementara menurut Kuiter dan Tonozuka (2001), S. canaliculatus dapat mencapai ukuran panjang sampai $30 \mathrm{~cm}$. Hal ini menunjukkan bahwa S.canaliculatus lebih menjadikan padang lamun sebagai daerah asuhan dan pembesaran, dan saat dewasa akan menuju ekosistem disekitarnya seperti terumbu karang untuk menghabiskan sebagian masa dewasanya pada ekosistem tersebut.

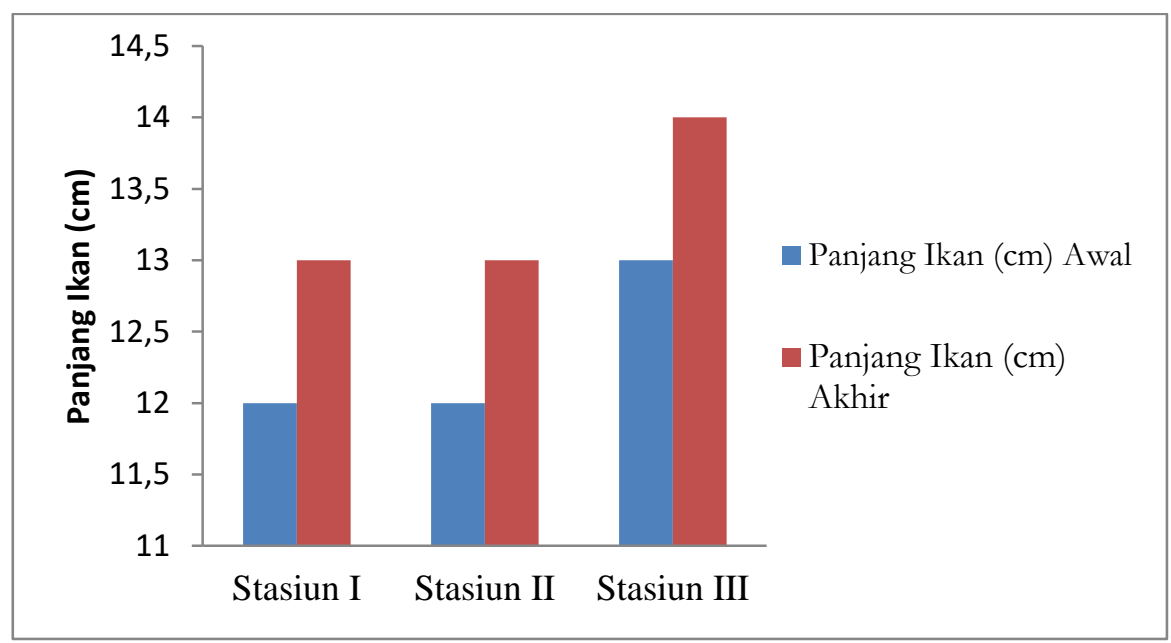

Gambar 10. Pertumbuhan Panjang Ikan Baronang

Hutomo (1985) juga menemukan kisaran ukuran S. canaliculatus 1,315,2 cm pada ekosistem padang lamun perairan Teluk Banten. Sementara Hasil penelitan Munira (2010) pada ekosistem padang lamun perairan Selat Lonthor 
kepulauan Banda-Maluku menemukan S.canaliculatus berukuran kecil antara 4,5 - 12,5 cm dan yang berukuran besar antara 16.5 - 20,5 cm ditemukan lebih menyukai lamun jenis Enhalus acorides dan Thalassia hemprichii, dimana mereka cenderung memilih lamun dengan morfologi daun yang besar dan lebar. Kondisi ini diduga mampu menyediakan relung ekologik bagi ikan sebagai tempat asuhan dan pembesaran.

\subsection{Aspek Pengelolaan}

Pengelolaan perikanan dalam rangka mempertahankan hasil maksimum dari sumberdaya dapat dilakukan melalui berbagi pendekatan, termasuk pendekatan secara biologi. Pendekatan secara biologi ini dilakukan dengan mengkonservasi stok ikan dan menhindari kondisi tangkap lebih. Diharapkan ikan yang ditangkap jumlahnya seimbang dengan rekruitmen alamiahnya.

Agar populasi sumberdaya ikan baronang di Pulau Sembilan tetap berlanjut, diperlukan usaha-usaha sejak dini untuk mempertahankan kelestarian sumberdaya ini.

1. Perlindungan terhadap habitat

Tingginya aktivitas masyarakat di sekitar padang lamun Perairan Pulau Sembilan seperti pembangunan transportasi laut, penggalian pasir, dan pelabuhan, baik secara langsung maupun tidak langsung dapat mempengaruhi eksistensi lamun dan lambat laun akan mengganggu peran ekologis padang lamun sebagai daerah perlindungan maupun mencari makan bagi ikan baronang dan biota laut lainnya. Untuk mengantisipasi hal ini, perlu dilakukan pengawasan maupun pembatasan (zonasi) terhadap aktivitas-aktivitas tersebut sehingga upaya pemanfaatan dan perlindungan habitat dapat berlangsung secara seimbang.

2. Pengaturan ukuran mata jaring

Jaring pantai yang digunakan dalam penelitian ini adalah yang lazim dipakai oleh nelayan setempat dengan mata jaring berukuran kecil dan hasil tangkapan yang di peroleh sebagian besar adalah anakan ikan baronang. Oleh karena itu, dalam rangka menyediakan kesempatan hidup bagi anakan ikan baronang, ukuran mata jaring yang digunakan perlu diperbesar, sehingga ukuran minimal hasil tangkapan lebih besar. Penggunaan jaring insang atau jaring pantai dengan ukuran mata jaring yang lebih besar memungkinkan ikan hasil tangkapan yang diperoleh 
adalah ikan-ikan dewasa sedangkan juvenil atau ikan ukuran anakan bisa tetap tumbuh dan berkembang. Hal praktis yang dapat dilakukan adalah melibatkan nelayan untuk berpatisipasi menjaga kelestarian stok ikan dengan cara memberikan pengertian mengenai dampak negatif dari penggunaan alat tangkap dengan ukuran mata jaring yang berukuran kecil.

\section{Melakukan kegiatan budidaya}

Usaha penangkapan ikan baronang di padang lamun Pulau Sembilan tidak hanya untuk memenuhi kebetuhan komsumsi namun juga untuk dimanfaatkan sebagai ikan umpan. Kondisi ini akan memberikan tekanan terhadap ikan-ikan berukan kecil. Salah satu alternatif dalam rangka melindungi ikan-ikan tersebut adalah menyediakan ikan umpan termasuk didalamnya ikan komsumsi melalui kegiatan budidaya. Kegiatan budidaya ini juga diharapkan dapat mengurangi tekanan penangkapan ikan di padang lamun, sehingga ketersediaan sumberdaya ikan-ikan muda termasuk ikan barong di padang lamun pulau sembilan dapat berkelanjutan (Munira 2010 ).

Sebagian besar operasi penangkapan ikan di padang lamun Pulau Sembilan dilakukan menggunakan jaring pantai dengan ukuran mata jaring yang kecil $(0.3$ inci ) sehingga selektifitasnya relatif rendah dan sebagian kecil lainnya menggunakan jaring insang dengan ukuran mata jaring yang lebih besar (2 inci ) adanya kenyataan bahwa sebagian kecil nelayan yang menggunakan jaring pantai kadang melepaskan kembali ikan hasil tangkapannya yang berukuran kecil ketika tidak dimanfatkan sebagai ikan umpan (Kelompok Nelayan), merupakan suatu hal yang positif. Apabila tindakan ini dapat diikuti oleh setiap nelayan yang menggunakan jaring pantai tentunya dapat mendukung upaya pengelolaan sumberdaya ikan baronang dan ikan lainnya di padang lamun Pulau Sembilan.

\section{Penutup}

\subsection{Kesimpulan}

1. Kerapatan lamun yang di amati terdapat tinggi pada stasiun I dan III berbeda nilai kerapatan pada stasiun II lebih rendah dari pada stasiun I dan III, dengan ditemukan tiga jenis padang lamun diantaranya Cymodocea serrulata, Halodule uninervis dan Syringodium iseotifolium memiliki nilai kerapatan termasuk kategori jarang di lokasi penelitian. Penutupan lamun yang tinggi pada stasiun I dan III berbeda nilai penutupan pada stasiun II lebih rendah dari pada 
stasiun I dan III, hal ini disebabkan karena di lokasi penelitian padang lamun termasuk kategori jarang sehingga perentase penutupun dengan nilai penutupan yang rendah.

2. Pertumbuhan ikan baronang di stasiun II dan III berbeda. Nilai pertumbuhan pada bagian stasiun I lebih besar dari pada stasiun II dan III, hal ini menunjukan bahwa di staiun I lebih produktif dikarenakan kerapatan padang lamun yang bagus dan mendukung pertumbuhan ikan baronang.

\subsection{Saran}

1. Perlu penelitian lebih lanjut agar mendapatkan data yang lebih komprehensif, sebaiknya dilakukan penelitian pembanding dengan waktu pengamatan yang relatif lama agar mendapatkan hasil yang maksimal dalam pemanfaatan ekosistem padang lamun untuk kegiatan budidaya ikan baronang yang ramah lingkungan tanpa merusak ekosistem lainnya.

2. Perlu dilakukan penelitian mengenai aspek reproduksi sehingga diketahui musim pemijahan ikan baronang diperairan pulau sembilan khususnya dipulau liang-liang.

\section{Daftar Pustaka}

Allen, G. 1999. Marine Fishes of South-East Asia; A guide for anglers and divers. Periplus Editions. Singapore. 292 pp.

Azkab MH. 2987. Ada apa dengan lamun. Oseana 31(3):45-55

Basyari, A., Danakusumah, Philip, T.I., Pramu S., Mustahal, Isyra, M., 1987. Budidaya Ikan Baronang (Siganus sp). Sub Balai Penelitian Budidaya Pantai Bojonegoro. Semarang. 12-13 hal.

Brower JE, Zar JH, Ende von CN. 1990. Field and laboratory methods for general ecology. Dubuque: WCB Publishers.

Dinas Kelautan dan Perikanan, 2014. Kualitas Air Bagi Pengolahan Sumberdaya Hayati Lingkungan Perairan.Pulau Sembilan. Kabupaten Sinjai

English S, Wilkinson C, Baker V. 1994. Survey mannual for tropical marine resource. Townville, Australia: ASEAN-Australia Marine Science Project: Living Coastal Resources by Australian Institute of Marine science.

Hemingga, A.M \& C.M. Duarte. 2000. Seagrass Ecology. Candbridge University Press. New York. 322 pp.

Hutomo, M. 1985. Telaah Ekologik Komunitas Ikan padang lamun (Seagrass, Antophyta) di perairan Teluk Banten. Disertasi Fakultas Pasca Sarjana IPB. Bogor. 299 pp.

Kiswara W. 1989. Struktur komunitas padang lamun perairan Indonesia. Inventarisasi dan evaluasi potensi laut pesisir II. Jakarta: Pusat Penelitian dan Pengembangan-LIPI. 
Kordi.M.G.H. 2009. Budidaya Perairan. Buku II. Citra Aditya Bakti. Bandung. $964 \mathrm{pp}$.

Kuitern RH and Debelius H. 2006. Word atlas of marine fishes. Franffurt: IKANUnterwasserachic. $358 \mathrm{p}$

Munira. 2010. Distribusi dan potensi Stok Ikan Baronang (Siganus canaliculatus) di Padang lamun Selat Lonthoir, Kepulauan Banda, Maluku. Tesis Sekolah PascaSarjana Institut Pertanian Bogor.

Nienhuis PH, Coosen J Kiswara W. 1989. Community Structure and biomassa distribution of seagrass and macrofauna in The Flores Sea, Indonesia. Neth J Sea Res. 23(2):197-214.

Zulkifli, Efriyeldi. 2003. Kandungan zat hara dalam air poros dan air permukaan padang lamun Bintan Timur Riau. Jurnal Natur Indonesia 5: 139-144. 